\title{
Hearing in Children With Type I Diabetes Mellitus
}

\author{
Claudia Fukuda ${ }^{\mathrm{a}}$, Liliane Desgualdo Pereira ${ }^{\mathrm{b}}$, Pedro Luiz Mangabeira Albernaz ${ }^{\mathrm{a}}$, \\ Angela M. Spinola e Castro ${ }^{c}$, Marisa de Lemos ${ }^{\mathrm{d}}$, \\ Patricia Gushikem ${ }^{\mathrm{d}}$, Ana Paula Perez ${ }^{\mathrm{d}, \mathrm{e}}$
}

\begin{abstract}
Background: Diabetes Mellitus has been regarded as a cause of hearing loss for many years. This study was designed to analyze the effect on the inner ear affection by diabetes mellitus in children.

Methods: Thirty type I diabetic and thirty non-diabetic children with ages ranging from 7 to 12 years old, perfectly paired regarding sex, age, cultural and social-economic status, were evaluated by pure tone audiometry, speech audiometry, high frequency audiometry and distortion product otoacoustic emissions (DPOAE).
\end{abstract}

Results: Diabetic children exhibited slightly elevated thresholds in pure tone audiometry at 250, 2,000,3,000, 4,000, 6,000 and 8,000 $\mathrm{Hz}$ frequencies. No statistical difference was found between results of speech discrimination, high frequency audiometry or DPOAE.

Conclusions: Diabetic children hear slightly less than non-diabetic children, and this does not seem to be related to impaired function of outer hair cells.

Keywords: Spontaneous otoacoustic emissions; Hearing test; Cochlea; Hypoglycaemia; Hyperinsulinism

\footnotetext{
Manuscript accepted for publication December 14, 2012

${ }^{a}$ Department of Otorhinolaryngology and Head-Neck Surgery, Federal University of Sao Paulo, Sao Paulo, Brazil

${ }^{\mathrm{b}}$ Audiology Division, Head of the Department of Hearing, Speech and Language Disorders (Departamento de Fonoaudiologia), Federal University of Sao Paulo, Sao Paulo, Brazil

${ }^{\mathrm{c}}$ Department of Pediatrics, Federal University of Sao Paulo, Division of Pediatric Endocrinology, Sao Paulo Hospital, Brazil

${ }^{\mathrm{d}}$ Human Comunication Disorders at the Federal University of Sao Paulo, Brazil

${ }^{\mathrm{e} C}$ Corresponding author: Ana Paula Perez, Rua Dr. Oswaldo Cruz 446, apto 161, Boqueirao, Santos, Brazil. Email: popiperez@ig.com.br
}

doi: http://dx.doi.org/10.4021/jem144e

\section{Introduction}

Since the nineteenth century, Diabetes Mellitus has been regarded as a cause of hearing loss [1]. Pathological investigations indicate the cochlea as the major lesion site, the stria vascularis being the most damaged structure $[2,3]$. Several authors [4-9] stated that diabetic individuals present hearing loss, or higher audiometric thresholds, particularly in high frequencies, more often than the general population. Most studies include patients over 45 in their population, and it is difficult to define whether hearing loss is due to presbycusis or not. This makes hearing impairment prevalence in these researches quite variable. Deviations in diabetic as well as in the control group increase the complexity of the problem. On the other hand, studies with lower age groups have demonstrated absence of audiometric alterations in Bekesy audiometry [10] as well as in speech and pure tone audiometry [11, 12], suggesting that younger diabetic individuals do not present hearing impairment. Despite the normal hearing sensitivity, their auditory system doesn't seem free from damage: otoacoustic emissions with lower amplitudes [13-15] and increase in wave latencies at auditory brainstem responses $[12,14,15]$ have been described.

Curiously, some authors [16, 17] verified the occurrence of frequent alterations in the glycemic and insulinemic curves in patients with cochleovestibular symptoms and audiometric abnormalities. Carbohydrate metabolism disturbances, hyperglycemia as well as hypoglycemia and hyperinsulinism, defined as Kraft's criteria [18] may be associated to such symptoms even in young patients. This study was designed to analyze the effect on the inner ear involvement by diabetes mellitus in children.

\section{Materials and Methods}

This research was carried out at the Department of Otorhinolaryngology and Head-Neck Surgery of the Federal University of Sao Paulo, with the collaboration of the division of Pediatric Endocrinology at the same institution. This study was approved by the Ethical Committee of the Federal Uni- 


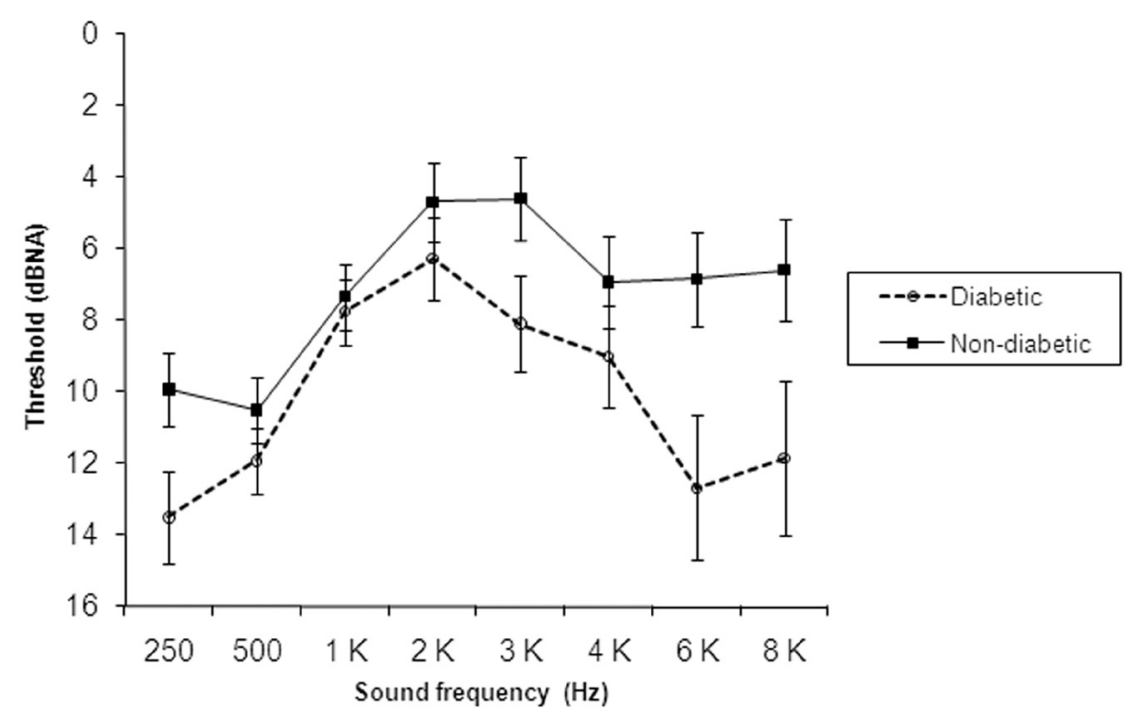

Figure 1. Pure tone audiometry means and standard deviations of each frequency threshold in diabetic and non-diabetic children.

versity of Sao Paulo, number 1153/00.

Thirty children ranging from 7 to 12 years old with type I Diabetes Mellitus were referred from the Diabetes ward of the Hospital Sao Paulo. Thirty non-diabetic children referred by pediatricians from the same hospital were considered the control group, pairing both groups according to sex, age, cultural and social-economic status.

Considered as inclusion factors were: normal otoscopy and tympanometry and presence of bilateral acoustic reflexes. Exclusion factors were: other metabolic or systemic diseases which could lead to hearing impairment; previous use of ototoxic drugs; acoustic, ear or cranio-encephalic trauma; perinatal events which could lead to hearing impairment; meningitis or encephalitis; ear surgery, familiar history of genetic deafness; middle ear chronic infection; history of multiple middle ear infections or more than four episodes of otitis media since birth to the date of the evaluation for this research.

The average age was $10 \pm 1.5$ years in each group, with 16 female and 14 male individuals in each group. The mean duration of diabetes was $20.3 \pm 15.37$ months. In the diabetic group, five children presented complaints suggestive of hearing impairment. In the non-diabetic group, eight children were suspected of having hearing impairment.

In order to avoid fatigue interference the evaluation was divided in 2 sessions. In the first, which took place in the morning, a clinical history was obtained, followed by physical examination, immittance measurements, and pure tone and speech audiometry. In the second, in the afternoon, 2 to 10 days after the first session, they were submitted to high frequency audiometry (HFA) and distortion product otoacoustic emissions (DPOAE).

Pure tone and speech audiometry were performed in a sound treated booth, with a two-channel Amplaid 455 audiometer. Thresholds were established at 250, 500, 1,000, 2,000, 3,000, 4,000, 6,000 and 8,000 Hz frequencies. Word recognition score (WRS) was also assessed in each ear. The equipment for the immittance tests consisted of a Siemens SD 300 automatic immittance meter with Telephonics TDH 39P earphones.

High frequency audiometry was performed in a sound treated room, with a Kamplex-AS $10 \mathrm{HF}$ audiometer and Koss HV/PRO digital phones. Air conduction thresholds were measured in $\mathrm{dB} H \mathrm{HL}$ with pure tone frequencies of 8 to $18 \mathrm{KHz}$.

DPOAE was analyzed in an acoustically treated room, with a GSI60 Grason-Stadler equipment, following the Darmouth Hitchcock Medical Center (DHMC) protocol (included in the device manual), which uses two pure tones as stimuli, both of $70 \mathrm{~dB}$ NPS intensity and $1.2 \mathrm{f} 2 / \mathrm{fl}$ frequency ratio. For analysis, distortion product amplitude was used at a geometric mean of $f 1$ and $f 2$, which were 531, 687, 843, $1,093,1,375,1,750,2,187,2,781,3,500,4,375$ and 5,500 Hz. Anova test was employed with a 0.05 (5\%) cut-off significance level.

\section{Results}

In audiometry, significant effects were group and sound frequency ( $\mathrm{F}<0.001$ significance). Ear laterality was not significant, so both ears were grouped. Diabetic children presented significantly greater thresholds at 250, 500, 2,000, 3,000, 4,000, 6,000, and 8,000 Hz frequencies (Fig. 1).

There was no statistically significant difference between both groups in speech audiometry $(\mathrm{F}=0.1183)$, high fre- 
quency audiometry $(\mathrm{F}=0.5348)$ and otoacoustic emissions $(\mathrm{F}=0.6527)$. The diabetic group presented slightly worse WRS results in the left ear $(97.60 \pm 3.73 \%)$ as opposed to the non-diabetic $(99.07 \pm 2.50 \%)$. However, the difference is not statistically significant.

\section{Discussion}

The absence of alterations in pure tone and speech audiometry has been the most common finding in diabetic children and teenagers $[11,12]$, although threshold raise has been described at 6 and $8 \mathrm{KHz}$ frequencies, reported to be due to microvascular complications [19].

In this study most children presented thresholds within normal ranges but the group comparison revealed that hearing thresholds in diabetic children were more elevated than in non-diabetic one. Other clinical trials have been able to show means of auditory thresholds of diabetic patients higher than those of control group in all frequencies [20,21]. The fact that this difference is slight could explain why hearing symptoms are not usually valued or stated. Some diabetic children presented abnormal audiometry results, which did not appear in the non-diabetic group, but no audiometric pattern was depicted for all cases. Thresholds were raised either in low or high frequencies, sometimes in both. The last is an inverted $U$ curve. This type of curve has been attributed to metabolic disturbances, especially hypoglycemia and hyperinsulinism [22]. This elevation in the audiometric thresholds may have occured due to periods of hypoglycemia and hypersinsulinism. Both reduce the function of sodium and potassium pumps in the inner ear, rise sodium concentration in the endolymph and alterate fluid dynamics of cochlear fluid with subsequent endolymphatic hydrops [16]. Therefore, this threshold increase may be transient. Another possible explanation is the reduction of outer hair cells activity associated to the production of free radicals in diabetes, especially in those cases with greater impairment at 6 and/or $8 \mathrm{kHz}$ frequencies. As diabetes progresses, either the stria vascularis capillary wall thickens or there is hair cell and spiral ganglia loss $[2,23]$.

The outcome of pure tone audiometry did not follow the results of high frequency audiometry. Previous studies with high frequency audiometry in adults with juvenile diabetes revealed no statistical difference, although thresholds of diabetics were higher [24]. One possible explanation could be the great variability of responses, which occurs even in normal individuals, making the comparisons between groups difficult, particularly in studies with small samples. High frequency audiometry has been proposed in early diagnosis of cochlear disorders as noise-induced hearing loss and ototoxicity and can be useful for monitoring hearing changes in the evolution of the diabetes, focusing patients with diminished kidney function.
Regarding speech discrimination, other studies with diabetic individuals did not reveal abnormalities [11, 24, 25]. In this study, diabetic children presented a tendency to lower values of WRS, but the difference was not statistically significant. Similar results had already been reported [26] and according to them, diabetic individuals present discrete alterations in speech discrimination and in audiometry with distorted speech, both suggesting retrocochlear lesion.

In Diabetes Mellitus, the impairment of outer hair cells is not yet well established $[23,27]$. The amplitude reduction in otoacoustic emissions observed in diabetic individuals has been attributed to pathological alterations in the inner ear, especially reduction in number of outer hair cells, even without hearing impairment [13] and has also been explained by metabolic complications, such as non-enzymatic glicosilation, which could lead to outer hair cell malfunction [14]. In the DPOAE results encountered in this study, the absence of amplitude reduction in the diabetic group may have happened because of the inner ear preservation or because the audiometric thresholds were not high enough to appear in the DPgram. Besides, considering the possibility of a threshold increase in audiometry being a result of endolymphatic hydrops, in which outer hair cells are not the first to be impaired, the otoacoustic emissions would not be reduced, since normal or almost normal amplitudes of otoacoustic emissions were observed in patients with Meniere's disease and thresholds up to 50dB NA [28, 29].

This study suggest that diabetic children have the threshold of hearing a little higher than children without diabetes, and it does not seem to be related to dysfunction of outer hair cells.

\section{Acknowledgement}

This study was financially supported by the Conselho Nacional de Desenvolvimento Cientifico e Tecnologico (CNPq), Brasilia, Brazil.

\section{References}

1. Jordao AMD. Consideration sur un cas du diabete. Union Medicale du Paris. 1857; 11: 446.

2. Jorgensen MB. Changes of aging in the inner ear, and inner ear in diabetes mellitus. Histological studies. Acta Otolaryngol Suppl. 1962; 188: 125-128.

3. Naufal PM, Schuknecht HF. Vestibular, facial, and oculomotor neuropathy in diabetes mellitus. Arch Otolaryngol. 1972;96(5):468-474.

4. Camisasca L. [Examination of the cochleovestibular apparatus in diabetes mellitus; preliminary note]. G Sci Mediche. 1950;5(3):45-49.

5. Profazio A, Baravelli P. [Auditory function in diabetes]. 
Otorinolaringol Ital. 1959;28:103-111.

6. Rosen Z, Davis E. Microangiopathy in diabetics with hearing disorders. Eye Ear Nose Throat Mon. 1971;50(12):479-482.

7. Kakarlapudi V, Sawyer R, Staecker H. The effect of diabetes on sensorineural hearing loss. Otol Neurotol. 2003;24(3):382-386.

8. Frisina ST, Mapes F, Kim S, Frisina DR, Frisina RD. Characterization of hearing loss in aged type II diabetics. Hear Res. 2006;211(1-2):103-113.

9. Vaughan N, James K, McDermott D, Griest S, Fausti S. A 5-year prospective study of diabetes and hearing loss in a veteran population. Otol Neurotol. 2006;27(1):3743.

10. Marshak G, Anderson CV. Bekesy audiometry with juvenile-onset diabetics. J Aud Res. 1968; 8, 323-330.

11. Sieger A, White NH, Skinner MW, Spector GJ. Auditory function in children with diabetes mellitus. Ann Otol Rhinol Laryngol. 1983;92(3 Pt 1):237-241.

12. Niedzielska G, Katska E. ABR disturbances in children with insulin dependent diabetes mellitus. Int J Pediatr Otorhinolaryngol. 1998;44(1):1-4.

13. Di Leo MA, Di Nardo W, Cercone S, Ciervo A, Lo Monaco M, Greco AV, Paludetti G, et al. Cochlear dysfunction in IDDM patients with subclinical peripheral neuropathy. Diabetes Care. 1997;20(5):824-828.

14. Lisowska G, Namyslowski G, Morawski K, Strojek K. Cochlear dysfunction and diabetic microangiopathy. Scand Audiol Suppl. 200152):199-203.

15. Dabrowski M, Mielnik-Niedzielska G, Nowakowski A. Involvement of the auditory organ in type 1 diabetes mellitus. Endokrynol Pol. 2011;62(2):138-144.

16. Mangabeira Albernaz PL, Fukuda Y. Glucose, insulin and inner ear pathology. Acta Otolaryngol. 1984;97(56):496-501.

17. Proctor CA, Proctor TB, Proctor B. Etiology and treatment of fluid retention (hydrops) in Meniere's syndrome. Ear Nose Throat J. 1992;71(12):631-635.

18. Kraft JR. Detection of diabetes mellitus in situ (occult diabetes). Lab med.1975; 6: 10-22.

19. Virtaniemi J, Laakso M, Nuutinen J, Karjalainen S, Var- tiainen E. Hearing thresholds in insulin-dependent diabetic patients. J Laryngol Otol. 1994;108(10):837-841.

20. Ferrer JP, Biurrun O, Lorente J, Conget JI, de Espana R, Esmatjes E, Gomis R. Auditory function in young patients with type 1 diabetes mellitus. Diabetes Res Clin Pract. 1991;11(1):17-22.

21. Okhovat SA, Moaddab MH, Okhovat SH, Al-Azab AA, Saleh FA, Oshaghi S, Abdeyazdan Z. Evaluation of hearing loss in juvenile insulin dependent patients with diabetes mellitus. J Res Med Sci. 2011;16(2):179-183.

22. Mangabeira Albernaz PL. Doencas metabolicas da orelha interna. Rev Bras Med Otorrinolaringol. 1995; 2(1): 18-22.

23. Triana RJ, Suits GW, Garrison S, Prazma J, Brechtelsbauer PB, Michaelis OE, Pillsbury HC. Inner ear damage secondary to diabetes mellitus. I. Changes in adolescent SHR/N-cp rats. Arch Otolaryngol Head Neck Surg. 1991;117(6):635-640.

24. Osterhammel D, Christau B. High frequency audiometry and stapedius muscle reflex thresholds in juvenile diabetics. Scand Audiol. 1980;9(1):13-18.

25. Dieroff HG, Schuhmann G, Westermann E. Hearing disease in Diabetes Mellitus. In: Claussen CF, Kirtane MV, Schlitter K. Vertigo, nausea, tinnitus and hypoacusia in metabolic disorders - Proceedings of the XVth Scientific Meeting of the Neurootological and Equilibriometric Society Amsterdam: Elsevier Science. 1988: 361-364.

26. Axelsson A, Fagerberg SE. Auditory function in diabetics. Acta Otolaryngol. 1968;66(1):49-64.

27. Nageris B, Hadar T, Feinmesser M, Elidan J. Cochlear histopathologic analysis in diabetic rats. Am J Otol. 1998;19(1):63-65.

28. Ohlms LA, Lonsbury-Martin BL, Martin GK. Acoustic-distortion products: separation of sensory from neural dysfunction in sensorineural hearing loss in human beings and rabbits. Otolaryngol Head Neck Surg. 1991;104(2):159-174.

29. Fetterman BL. Distortion-product otoacoustic emissions and cochlear microphonics: relationships in patients with and without endolymphatic hydrops. Laryngoscope. $2001 ; 111(6): 946-954$. 